\title{
ŚRODKOWONEOLITYCZNE ZNALEZISKA TALERZY Z NIŻU POLSKI
}

\author{
THE MIDDLE NEOLITHIC PLATES FINDINGS \\ FROM THE POLISH LOWLAND
}

\author{
Seweryn Rzepecki \\ Instytut Archeologii, Uniwersytet Łódzki \\ ul. Pomorska 96, 91-402 Łódź, Poland
}

ABSTRACT. In this paper the author concentrates on the problem of the occurrence of clay plates within the region of the Polish Lowland. The sources are findings known from the literature as well as those excavated recently. Comparative analyses related territorially to Europe and chronologically to the period $4400-3800 \mathrm{BC}$.

Płaskie, dyskokształtne naczynia o średnicy przynajmniej kilkunastu centymetrów, określane jako talerze, placki gliniane, Esstellern, Tellern, Backtellern, Tonscheiben (niem.) czy plats-à-pain (franc.), są niewątpliwie jednym z najciekawszych fenomenów neolitu Europy. W polskich badaniach nad KPL ${ }^{1}$ panuje zgoda co do tego, iż talerze należy interpretować jako element „obcy”, nie związany z miejscową tradycja kulturowa. Kontrowersje dotyczą natomiast identyfikacji źródeł ich napływu.

Na przykład K. Jażdżewski w swej pracy z 1970 roku pisał:

${ }^{1}$ W pracy użyto następujących skrótów: GB - grupa Bischeim; GBN-V - grupa Bylany Nade-vsi; GB-O - grupa Breubach-Obergarben; GB KPL - grupa baalberska kultury pucharów lejkowatych; GG grupa Gatersleben; GE - grupa Entzheim; GM - grupa Menneville; GO - grupa ocicka; Gox - grupa Oxie; GS - grupa Siggeneben; Gsa - grupa Satrup; GSch - grupa Schwieberdingen; Gsva - grupa Svaleklint; Gsve - grupa Svenstrop; GV - grupa Volling; Kca - kultura Cartaillod; KC - kultura Cerny; KCh - kultura Chassey; KJ - kultura jordanowska; KM - kultura Michelsberg; KMCM - kultura morawskiej ceramiki malowanej; KP - kultura Pfyn; KPL - kultura pucharów lejkowatych; KR - kultura Rössen; KSch - kultura Schussenried.

Czas, jaki upłynął od złożenia pracy do druku, przyniósł zarówno nowe odkrycia talerzy, jak i nową propozycję taksonomii wczesnej KPL. Zainteresowanych Czytelników odsyłam do pracy S. Rzepeckiego (2001). 
Po pierwsze nie odnajduje się na południu wszystkich form najstarszej ceramiki kultury pucharów lejkowatych z fazy A (C.J. Beckera), jak np. plaskich talerzy glinianych, pojawiajacych się w bardziej północnych połaciach obszaru kultury pucharów lejkowatych (od Kujaw na wschodzie - tu z Sarnowa w pow. włocławskim - aż do Holandii na zachodzie, w Skandynawii południowej i także jeszcze w Niemczech środkowych), których natomiast nie spotyka się dalej na południu, przede wszystkim w obrębie kultur naddunajskich. Natomiast sa one pospolitym zjawiskiem raczej na zachodzie, w kulturze michelsberskiej oraz szasejskokortajodzko-lagocańskiej [Chassey-Cortaillod-Lagozza] ${ }^{2}$.

W podobnym kierunku zmierzały poszukiwania analogii dla talerzy odkrytych na lendzielskich stanowiskach w Targowisku ${ }^{3}$ i Raciborzu-Ocicach ${ }^{4}$. Te ostatnie J.K. Kozłowski określił jako ,plats-à-pain" ${ }^{\text {. }}$

Inaczej problem ten widział T. Wiślański:

Na powiązania [KPL - przyp. S.Rz.] z późnym kręgiem lendzielskim (ceramiki niemalowanej) wskazuja: prawie zupełny brak ornamentyki, karbowanie brzegów, niektóre detale, np. palczaste zakończenie uch, czy wreszcie szereg form naczyń (m.in. talerze, niektóre amfory i misy) ${ }^{6}$.

Z kolei w pracy A. Kośko, który zajął się późnoneolitycznym horyzontem występowania talerzy, ich pojawienie się wiązane jest $z$ oddziaływaniami populacji „,baalberskich”, które translokowały wzorce „michelsberskie”?. Brak jednak w ostatniej z cytowanych prac, z uwagi na horyzont chronologicznych zainteresowań Autora, odniesienia się do talerzy o proweniencji środkowoneolitycznej.

Tak więc pojawienie się talerzy na terenie dzisiejszej Polski wiązane było z oddziaływaniami zachodnioeuropejskimi ${ }^{8}$, lendzielskimi ${ }^{9}$ lub też podkreślano - w ich przekazaniu - rolę grupy północnej KPL ${ }^{10}$.

Próbą nowego spojrzenia na anonsowany problem jest poniższy artykuł. Analizy przeprowadzone zostaną w zawężeniu terytorialnym (Niż Polski) i chronologicznym (środkowy neolit). Zakres analizy porównawczej zostanie ograniczony do przedziału 4400-3800 BC, co odpowiada fazom I-II KPL ${ }^{11}$ na Kujawach, w których talerze stanowią element wyposażenia kulturowego wczesnej KPL. Artykuł składa się z trzech części. Pierwszą tworzy ,polska” perspektywa omawianego problemu, druga odpowiada na pytanie o miejsce znalezisk polskich w szerszym ujęciu, trzecia jest propozycją interpretacyjną.

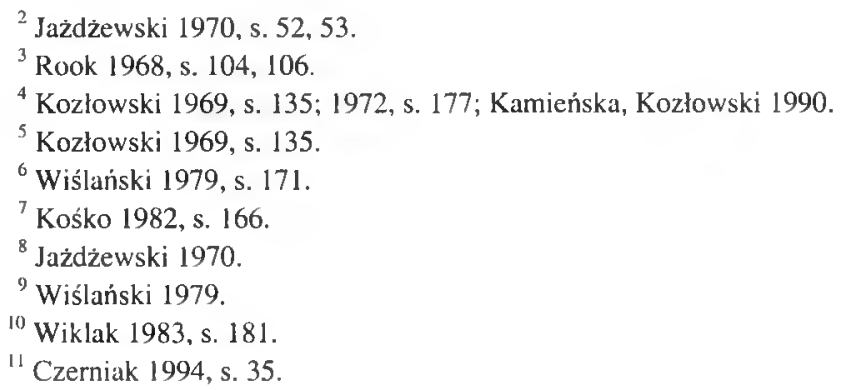




\section{I}

Do przeprowadzenia, diachronicznego w swym ujęciu, opisu znalezisk użyto typologii talerzy opracowanej przez A. Kośko ${ }^{12}$. Warto przypomnieć tu ogólnie zasadę typologizacji talerzy.

XIIA - talerz płaski,

XIIB - talerz głęboki,

XIIB1 - jw., o łagodnym spojeniu ścianki bocznej z dnem,

XIIB2 - jw., o podkreślonej odrębności morfologicznej ścianki bocznej i dna.

Niestety, ze względu na stan zachowania (i publikacji) źródeł ograniczę się jedynie do ich podziału na talerze płaskie (XIIA) oraz głębokie (XIIB).

\section{FAZA I KPL}

Łącko, woj. kujawsko-pomorskie, stan. 6. Z powodu złego stanu zachowania materiału ceramicznego trudno było dokładnie ustalić liczbę opisywanych form. Należy sądzić, że zarejestrowano pozostałości maksymalnie 8 talerzy. Rozpoznano typy:

- XIIA - 1 szt.

- XIIB - 7 do 8 egz. (w 2 przypadkach zdobione) ${ }^{13}$.

Stanowisko datowane jest na fazę I KPL na Kujawach ${ }^{14}$ (ryc. 1: 1-3).

Łącko, woj. kujawsko-pomorskie, stan. 6A. Według informacji L. Domańskiej na stanowisku tym, datowanym na fazę I KPL, wystąpiły talerze, w tym okazy zdobione $^{15}$ (ryc. 1: 4).

Sarnowo, woj. kujawsko-pomorskie, stan. 1A. Wedle słów H. Wiklaka „talerze krążkowate znane są [w Sarnowie 1A - przyp. S.Rz.] z kilkunastu [16 - S.Rz.] egzemplarzy zachowanych $w$ mniejszych lub większych fragmentach"16. Sądząc z opisu, wszystkie należą do typu XIIB. Na kilku z nich zarejestrowano zdobienie. Warstwa kulturowa datowana jest na fazę I KPL na Kujawach ${ }^{17}$ (ryc. 1: 6-12).

Sarnowo, woj. kujawsko-pomorskie, stan. 1, grobowiec 8. Materiał KPL wystapił zarówno w obrębie nasypu, jak i warstwy kulturowej, jaką zaobserwowano pod nasypem. Talerze wystapiły zarówno w nasypie, jak i w warstwie ${ }^{18}$. W war-

\footnotetext{
12 Kośko 1981, s. 31 .

${ }^{13}$ Domańska, Kośko 1983, s. 20.

${ }^{14}$ Domańska, Kośko 1983.

${ }^{15}$ Domańska 1995, s. 11.

${ }^{16}$ Wiklak 1983, s. 181.

${ }^{17}$ Zob. też: Niesiołowska 1994, s. 325

${ }^{18}$ Wiklak 1980, s. 57.
} 

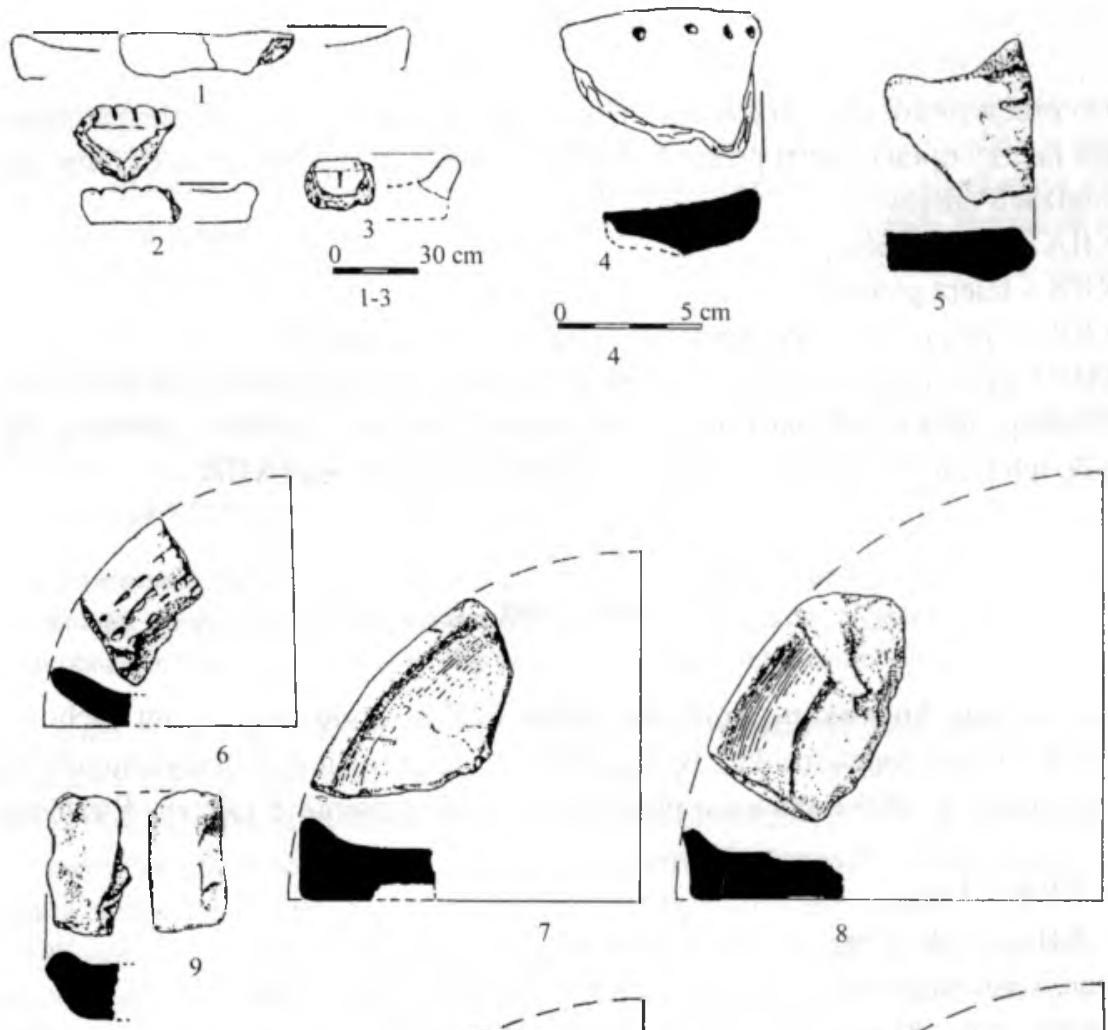

7

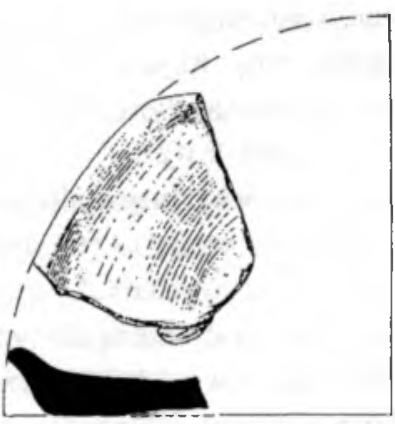

10

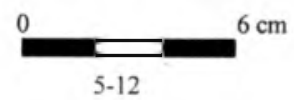

Ryc. 1. Wybór talerzy ze stanowisk fazy I KPL.

1-3-Łącko, stan. 6 (wg Domańska, Kośko 1983); 4-Łącko, stan. 6A (wg Domańska 1995); 5 - Sarnowo, stan, I (grobowiec 8); 6-12 - Samowo, stan. 1A (wg Niesiolowska 1994)

Fig. 1. Selection of plates from ties of the first phase of FBC.

1-3 - Łącko, site 6 (according to Domariska, Kośko 1983); 4 - Łącko, site 6A (according to Domańska 1995); 5 - Sannowo, site 1 (grave 8); 6-12-Sarnowo, site 1A (according to Niesiołowska 1994) 
stwie kulturowej i jamie 1 (znaleziska fazy I KPL) zarejestrowano ogółem 9 fragmentów talerzy, z których przynajmniej 2 są zdobione na krawędzi ${ }^{19}$ (ryc. 1: 5).

Sarnowo, woj. kujawsko-pomorskie, stan. 1, grobowiec 4. Zarejestrowano tu, w obrębie nasypu, 1 fragment talerza typu XIIB. Chronologia tego znaleziska jest niepewna. Materiały spod nasypu ( $\mathrm{z}$ warstwy kulturowej) pochodzą $\mathrm{z}$ fazy I KPL. Zaliczyć do nich należy również większość znalezisk z nasypu (w tym najprawdopodobniej talerz). Zajęcie jednoznacznego stanowiska utrudnia jednak występowanie wśród ceramiki z nasypu uciążliwych domieszek z fazy II $^{20}$.

\section{FAZA II KPL}

Inowrocław, woj. kujawsko-pomorskie, stan. 95. Wśród pozostałości trzech odrębnych jednostek osadniczych - resztek obozowisk ludności KPL z inicjalnego etapu fazy II - natrafiono na talerze typu XIIA i XIIB. Wystapily one w obrębie skupisk (obozowisk) I oraz $\mathrm{II}^{21}$. W skupisku I natrafiono na 2 talerze typu XIIA i 1 XIIB. W skupisku II 2 talerze określono jako typ XIIB, a 1 - XII. Poza tym 1 talerz typu XIIB wystapił poza czytelnymi skupiskami ${ }^{22}$. Niestety, w przypadku omawianego stanowiska należy liczyć się z niehomogennością zbiorów $w^{23}$ (ryc. 2: 1).

Kiełczewo, woj. wielkopolskie, stan. 45. W tym datowanym na fazę II (dokładniej jej końcowy odcinek) stanowisku KPL wystapiło 5 fragmentów talerzy, z czego przynajmniej 1 należy do typu XIIA/B. Pozostale natomiast do typu XIIB(? $)^{24}$ (ryc. 2: 4-6).

Kosin, woj. zachodniopomorskie, stan. 6. Ze stanowiskiem tym należy łączyć wystapienie 13 fragmentów talerzy. Sądząc z opisu, wszystkie należy określić jako typ XIIB ${ }^{25}$. Zespół ten był datowany na „późniejsze stadium rozwojowe fazy A/B" $\mathrm{KPL}^{26}$ lub miał nawiązywać do stanowisk typu Havenlev-Stengade ${ }^{27}$. W świetle badań z ostatnich kilku lat okazuje się jednak, że zespół z Kosina ma bezpośrednie analogie w końcowym okresie fazy II (zespoły typu Przybranówek). Świadczą o tym głównie nawiązania do kręgu późnolendzielskiego. Oczywiście, powstaje problem interpretacyjny. Czy mamy w tym przypadku do czynienia z efektem konwergencji,

${ }^{19}$ Np. Wiklak 1980; 1990; Czerniak 1994.

${ }^{20}$ Chmielewski 1952. Chciałbym w tym miejscu serdecznie podziękować Panu Prof. drowi hab. Ryszardowi Grygielowi, dyrektorowi Muzeum Archeologicznego i Etnograficznego w Lodzi, za możliwość autopsji materiałów KPL ze stanowisk 1 i 1 A w Sarnowie.

${ }^{21}$ Czerniak, Kośko 1993, s. 27.

${ }^{22}$ Czerniak, Kośko 1993, s. 8-26.

${ }^{23}$ Czemiak, Kośko 1993, s. 92, 93.

${ }^{24}$ Stempin 1995, s. 24.

${ }^{25}$ Wiślański, Czarnecki 1970, s. 79, 80 .

${ }^{26}$ Wiślański, Czarnecki 1970, s. 100.

${ }^{27}$ Wiślański 1983, s. 48. 

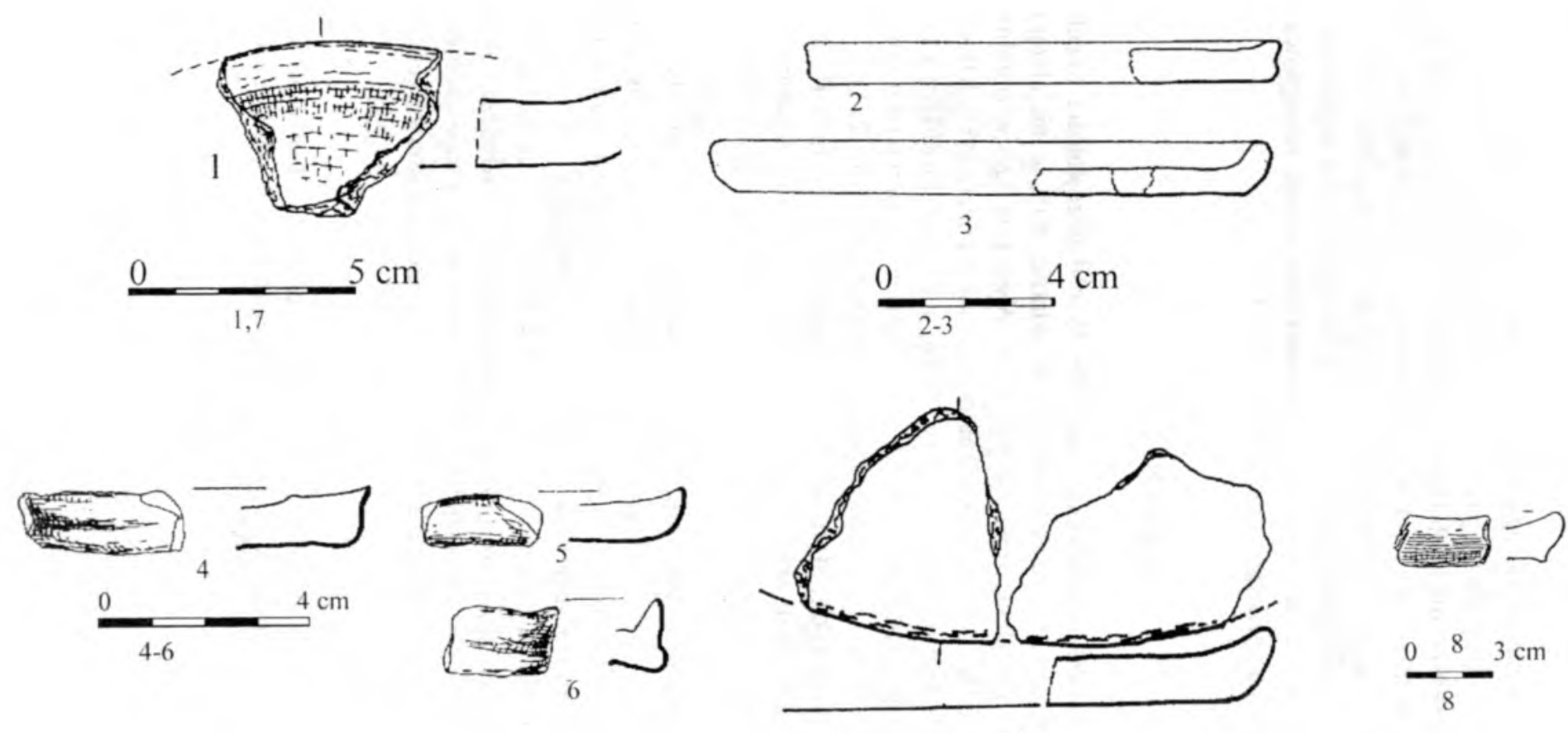

Ryc. 2. Wybór talerzy ze stanowisk faz II-IIIA? KPL.

1 - Inowroclaw, stan. 95 (wg Czerniak, Kośko 1993); 2-3 - Kosin, stan. 6 (wg Wiślański 1979); 4-6 - Kielczewo, stan. 45 (wg Stempin 1995); 7 - Przybranówek, stan. 43 (chata I) (wg Czemiak, Kośko 1993); 8 - Krępcewo, stan. 4 (wg Wiślański 1977)

Fig. 2. Selection of plates from sites of phases II-IIIA? of FBC

1 - Inowrocław, site 95 (according to Czemiak, Kośko 1993); 2-3 - Kosin, site 6 (according to Wiślański 1979); 4-6 - Kiełczewo, site 45 (according to Stempin 1995); 7 - Przybranówek, site 43 (house 1) (according to Czemiak, Kośko 1993); 8 - Krępcewo, site 4 (according to Wiślański 1977) 
czy raczej zespół z Kosina poświadcza oddziaływanie kujawsko-wielkopolskiej aglomeracji KPL? To pierwsze rozwiązanie, z uwagi na kierunek rozprzestrzeniania się cech "górowskich", jest co najmniej równie prawdopodobne jak drugie (ryc. 2: 2-3).

Przybranówek, woj. kujawsko-pomorskie, stan. 43. Materiały KPL wystapiły w pięciu samodzielnych skupiskach-chatach. W ich obrębie zarejestrowano:

chata 1: wśród 9 fragmentów talerzy wystapiły fragmenty typu: XIIB - 6 szt.; XIIA - 1 szt.; XII - 2 szt. $^{28}$ (ryc. $2: 7$ );

chata 2: zarejestrowano 1 fragment typu XIIB;

chata 3: wystapiły 2 fragmenty talerza, oba typu XIIB;

chata 4: wystapił 1 fragment talerza typu XIIB.

$\mathrm{Na}$ podstawie wszechstronnych analiz za najbardziej prawdopodobny uznano rotacyjny sposób zasiedlenia stanowiska przez grupy KPL. Najmłodszy zdaje się być zespół chaty 1, następnie istniało dwudomowe osiedle złożone $z$ chaty 2 i 3 (chaty 1-3 można datować na schyłkowy okres fazy II). Po jakimś czasie osadnicy KPL wrócili, by założyć osadę poświadczoną poprzez istnienie chaty 4 (przełom faz II i IIIA), a sekwencję zasiedlenia zamyka chata 5 (w której nie zarejestrowano talerzy), datowana na fazę IIIA ${ }^{29}$.

Sierakowo, woj. kujawsko-pomorskie, stan. 8. Zarejestrowano tu 1 pewny fragment talerza typu XIIB, podkreślić jednak również należy obecność płaskich „przęślików” przypominających omawiane formy (,minitalerzyki” wg A. Kośko) ${ }^{30}$. Stanowisko datowane jest na fazę II KPL na Kujawach.

FAZA IIIA

Krepcewo, woj. zachodniopomorskie, stan. 4. Wśród materiałów pochodzących $\mathrm{z}$ grobowca bezkomorowego KPL wystapił 1 fragment talerza typu XIIB ${ }^{31}$. Odnosząc to stanowisko do chronologii kujawskiej, moźna je datować na fazę IIIA(?) (ryc. $2: 8$ ).

Na zakończenie przeglądu źródeł należy jeszcze odnieść się do talerzy znanych z Kotowa ${ }^{32}$, które część badaczy skłonna jest datować na horyzont wczesnopucharowy ${ }^{33}$. Jest to oczywiście prawdopodobne, jednak istnieją poważne watpliwości co do chronologii stanowiska. A. Kośko pisał: „bardziej uzasadnione jest łączenie tale-

\footnotetext{
${ }^{28}$ Czerniak, Kośko 1993.

${ }^{29}$ Domańska, Rzepecki 2001, s. 37.

${ }^{311}$ Kośko. Prinke 1975, s. 13.

${ }^{31}$ Wiślański 1977, s. 93.

${ }^{32}$ Lipińska 1962, s. 304-306.

${ }^{33}$ Gabałówna 1970, s. 82; Wiklak 1983, s. 181.
} 


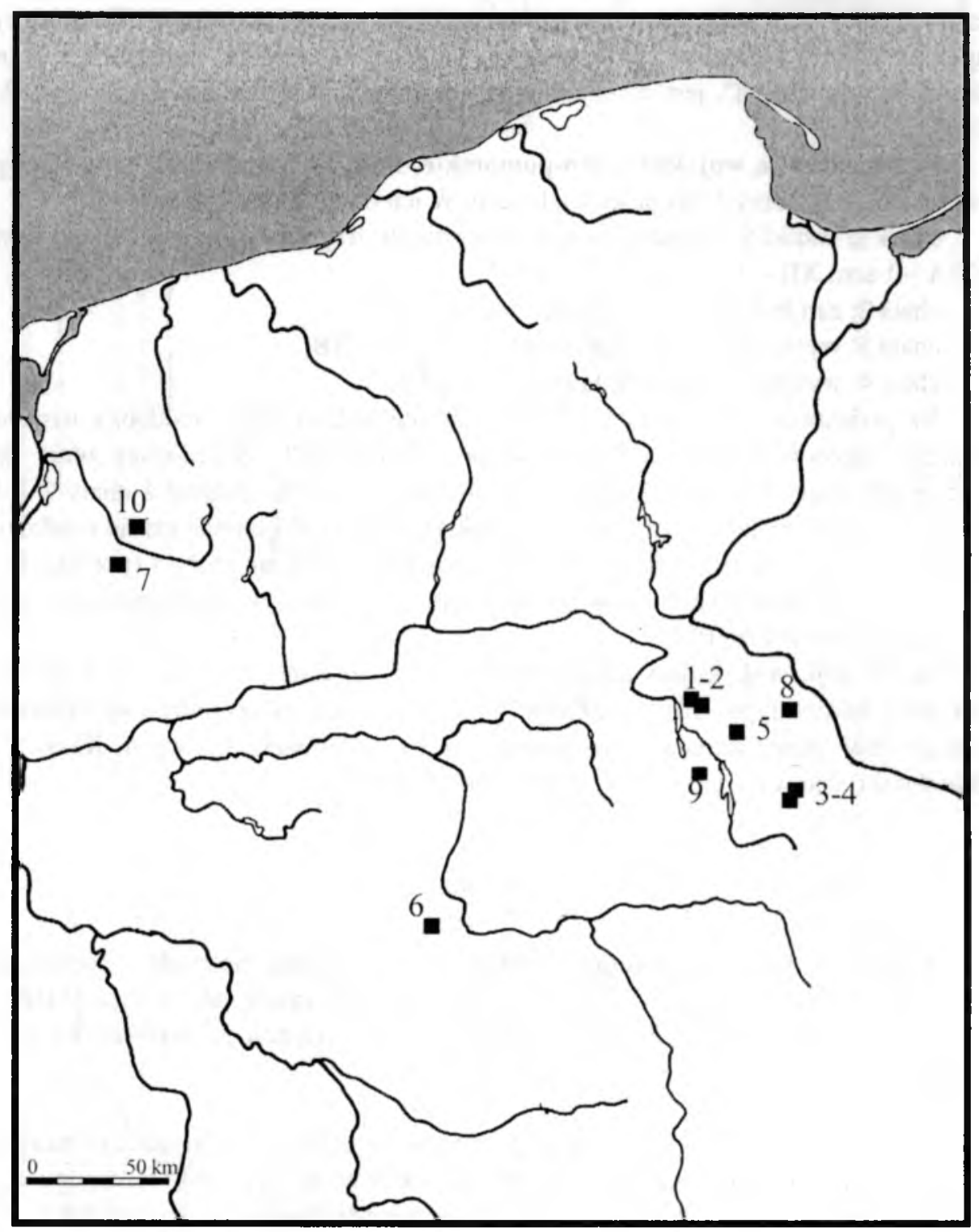

Ryc. 3. Rozmieszczenie środkowoneolitycznych znalezisk talerzy z terenu Niżu Polski.

1 - Łącko, stan. 6; 2 - Lącko, stan. 6A: 3 - Samowo, stan. 1; 4 - Sarnowo, stan. (A; 5 - Inowroclaw, stan. 95; 6- Kiełczewo. stan. 45; 7 - Kosin, stan. 6:8 - Przybranówek, stan. 43;9 - Sierakowo, stan. 8; 10 - Krępcewo, stan. 4

Fig. 3. Distribution of the middle neolithic findings of plates from the Polish Lowland.

1 - Łącko, site 6; 2-Lącko, site 6A;3-Samowo, site 1;4-Sarnowo, site 1A;5-Inowrocław, site 95;6-Kiełczewo, site 45; 7 - Kosin, site 6; 8 - Przybranówek, site 43;9 - Sierakowo, site 8; 10 - Krępcewo, site 4 
rzy »kotowskich $\mathrm{z}$ inwentarzem »lubońskim«" ${ }^{34}$. T. Wiślański donosi też o talerzach odkrytych na stanowiskach $w$ Sicinach $^{35}$ i Dębach-Krzywosądzu ${ }^{36}$. Jednak w publikacjach źródłowych W. Wojciechowskiego ${ }^{37}$ oraz M. Szmyt i J. Czebreszuka brak na ten temat informacji ${ }^{38}$.

$\mathrm{Na}$ opracowywanym terenie liczbę znalezisk talerzy można szacować (z uwagi na charakter źródeł i stan publikacji) na około 75. Należy podkreślić, iż talerze wystapiły wyłącznie w zachodniej części Niżu Polski (ryc. 3), z wyraźną koncentracja na Kujawach (być może jest to efekt stanu badań).

W kujawskim skupisku talerzy są one obecne w fazach I-II KPL, nie występuja natomiast $w$ inwentarzach fazy IIIA ${ }^{39}$. Obecność talerza na stanowisku w Krępcewie, którego chronologię można odnieść do fazy IIIA na Kujawach, może być efektem odmiennego tempa przemian stylistycznych lub odmiennych uwarunkowań genetycznych. Do kwestii tej jeszcze powrócimy.

Obecnie brak podstaw do twierdzeń o chronologicznym walorze podziału na talerze "płaskie" i „glębokie". Ostatnie występują częściej w interesującym nas okresie, wynika to chyba jedynie z większej „popularności” tej formy. Wydaje się natomiast, iż znaczenie chronologiczne można przypisać zdobieniom talerzy. Wystapiły one bowiem jedynie w zespołach fazy I KPL.

\section{II}

W badaniach nad genezą talerzy można wskazać kilka punktów zwrotnych. W najstarszych pracach można się spotkać, na przykład, z koncepcją o egipskiej genezie omawianego zjawiska ${ }^{40}$. Rozważano również możliwość wywodzenia talerzy z pokrywek $\mathrm{KCh}^{41}$.

W latach sześćdziesiątych i siedemdziesiątych przeważały opinie o związku talerzy z $\mathrm{KM}^{42}$. Podkreślano ich obecność w zespolach wszystkich faz tejże kultury ${ }^{43}$, jak również stosunkowo liczne znaleziska talerzy z jej terenu ${ }^{44}$. Sytuacja skomplikowała się $w$ efekcie badań przeprowadzonych w latach siedemdziesiątych na terenie Basenu Paryskiego. Zarejestrowano wtedy występowanie talerzy na stanowi-

\footnotetext{
${ }^{34}$ Kośko 1982, s. 162.

${ }^{35}$ Wiślański 1971, s. 89.

${ }^{36}$ Wiślański 1971 , s. 89.

${ }^{37}$ Wojciechowski 1972.

${ }^{38}$ Czebreszuk, Szmyt 1992.

${ }^{39}$ Czerniak, Kośko 1993, s. 115; Czerniak 1994, s. 76; Rzepecki 1999.

${ }^{40}$ Behrens 1963, s.140.

${ }^{41}$ Arnal, Burenez 1958, s. 68.

${ }^{42}$ Schwabedisen 1967, s. 453; Bailloud 1961, s. 509-511; 1971, s. 230.

${ }^{43}$ Lüning 1968, s. 83, Beilage 5.

${ }^{44} \mathrm{Na} 200$ stanowisk KM znanych w 1968, na 76 wystapily talerze: Lüning 1968, s. 67-69.
} 
skach GM - np. Berry-au-Bac. Cytowane stanowisko związane jest z faza protoMenneville $\mathrm{GM}^{45}$, która odpowiada okresowi istnienia GB i fazy III KR. Odkrycia te w powiązaniu z identyfikacją niezwykle archaicznych zespołów KM na tym terenie (np. Bazoches-sur-Vesle ${ }^{46}$ ) przyczyniły się do powstania koncepcji "fazy 0 " KM. Zakłada ona wcześniejszą - niż na terenach nadreńskich - genezę KM na obszarze Basenu Paryskiego ${ }^{47}$. Talerze miały się pojawić po raz pierwszy w zespołach wczesnej GM (a więc wcześniej niż na obszarach zachodnioniemieckich ${ }^{48}$ ), skąd trafiły do wczesnej KM i późnej KC (np. La Glaisiere) ${ }^{49}$. Za pośrednictwem społeczności $\mathrm{KM} \mathrm{z}$ opisywanego terenu talerze miały trafić dalej na wschód - do nadreńskich populacji KM.

Koncepcja Ch. Jeunesse spotkała się ze zdecydowana krytyką ze strony J. Lichardusa. Podkreśla on, że talerze występują w późnych typologicznie zespołach $\mathrm{KC}$ fazy Cerny-Barbuisse, które mogą być synchronizowane z wczesną KM (nie sq̨ więc od niej starsze). Zdaniem J. Lichardusa talerze należące do zespołów GM mogą być odniesione dopiero do fazy II KM z terenów nadreńskich ${ }^{50}$.

Daty radiowęglowe $z$ jednej strony sytuują rozwój GB i GM w okresie 4600$4300 \mathrm{BC}^{51}$ (możliwe byłoby więc współistnienie GM z najwcześniejszą KM), z drugiej zaś potwierdzają istnienie zespołów fazy Cerny-Barbuisse już około 4500 $\mathrm{BC}^{52}$ (potwierdzałoby to najwcześniejszą pozycję chronologiczną talerzy z terenów Basenu Paryskiego).

W dorzeczu Renu talerze pojawiają się około $4400 \mathrm{BC}$, wraz z zespołami fazy I/II $\mathrm{KM}^{53}$. Stają się również jedną z form przewodnich tejże kultury ${ }^{54}$, występując we wszystkich okresach jej rozwoju.

W okresie odpowiadającym wczesnej $\mathrm{KM}^{55}$ talerze trafiają również do społeczności bezpośrednio graniczących z KM. W środowiskach tych obecność talerzy interpretowana jest jako „wpływ” KM.

Nad górnym Renem obecność talerzy wzmiankowana bywa w związku z GE, GB-O, GSch i GB. Obecnie można powiedzieć, że talerze z pewnością wystapiły już w najwcześniejszych zespołach GE (np. Entzheim, Bleichheim ${ }^{56}$ ) (około $4400 / 4300-4100 \mathrm{BC}^{57}$ ). W tym samym zapewne czasie pojawiają się one, nieco

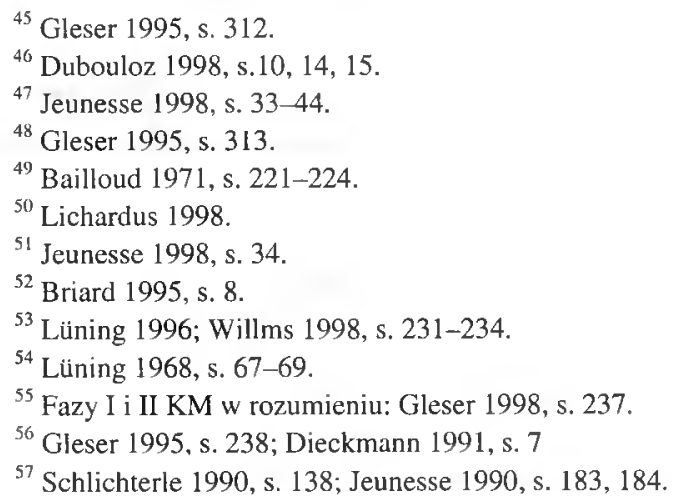


bardziej na południe, w społecznościach GB-O (Ihringen ${ }^{58}$ ). W świetle ostatnich badań obecność talerzy w GB (Hopfenberg ${ }^{59}$ ) i GSch (Schwieberdingen ${ }^{60}$ ) jest wątpliwa ${ }^{61}$. Talerze występują natomiast $w$ inwentarzach młodszej fazy GE (np. Entzheim, Sasbach-Jechtingen ${ }^{62}$ ). Około $4100 / 4050$ BC rozpoczyna się nowy etap obecności talerzy w alpejskich jednostkach poströsseńskich. Jest on związany z pojawieniem się w dorzeczu Neckaru KSch, której okres rozwoju przypada na 4100/4050-3800 BC B $^{3 .}$. Należy w tym miejscu przypomnieć stanowiska Ludwigsburg-Schlösslefeld ${ }^{64}$, Hochdorf II $^{65}$, Ehrenstein ${ }^{66}$. Warto zauważyć, że na stanowisku w Ehrenstein, gdzie naczynia w „stylu michelsberskim” stanowią 7\% ogółu naczyń $^{67}$, udział talerzy (w fazach Ehrenstein III-IV) stale wzrasta ${ }^{68}$.

W czasie, gdy nad Neckarem rozwija się KSch, impulsy KM trafiają również na teren wschodniej Szwajcarii - do KP. W inwentarzach jej starszej fazy - obok pucharów tulipanowatych - pojawiają się również talerze ${ }^{69}$. Faza ta jest datowana na okres 4150-3900 BC ${ }^{70}$. Talerze występują również w klasycznej (3900-3700 BC) fazie KP. Nieco później talerze trafiają do fazy klasycznej KCa (np. ZürichMozartstrasse $)^{71}$. Na podstawie datowań osady w Twann początek tej fazy należy synchronizować z $3900 \mathrm{BC}^{72}$. Pod koniec interesującego nas okresu talerze pojawiają się także w osadzie Zürich-Kanalisationssanierung Seefeld (warstwa 9) z fazy Pfyn/Altheim ${ }^{73}$.

W tym miejscu warto zwrócić uwagę na teren Czech. Na tym terenie talerze związane są z nowo wydzieloną jednostką kulturową - GBN-V. Jest to jednostka o charakterze synkretycznym, łącząca - według M. Zapotockýego - tradycje KPL,

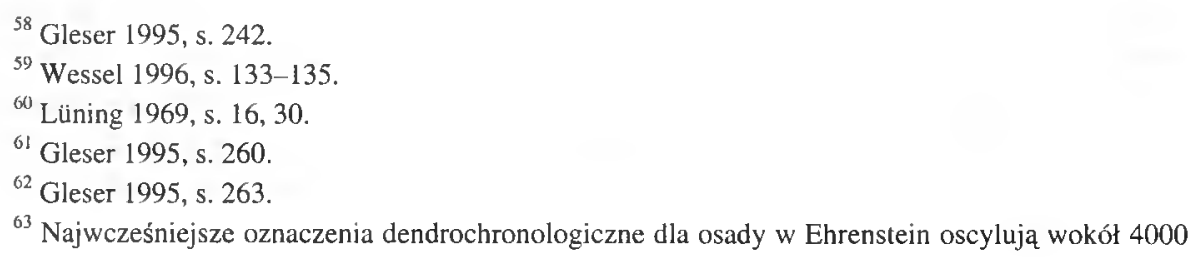
BC (Faza Ib chaty 5 uzyskała datę 3956/3955 BC), wobec czego geneza KSch datowana być musi na okres nieco wcześniejszy. Np.: Willms 1998, s. 237; Billamboz 1998, s. 144-165, tamże dalsza literatura. Zob. także: Lüning 1998, s. 282. Wg E. Gross-Klee młodsza faza KSch mogła wykształcić się nawet około 4250 BC, Gross-Klee 1998, s. 253.

${ }^{64}$ Lüning, Zürn 1977, s. 40.

${ }^{65}$ Keefer 1988, s. $78,79$.

${ }^{66}$ Lüning 1997, s. 57, 58, 66-72.

${ }^{67}$ Lüning 1997.

${ }^{68}$ Lüning 1997, s. 71.

${ }^{69}$ Schlenker 1998, s. 181. Por. także: Schlichterle 1998, s. 171

${ }^{70}$ Winiger 1990, s. 297; Gross, Ritzmann 1990, s. 161-165.

${ }^{71}$ Gross-Klee 1998, s. 249-256. Daty dendrochronologiczne dla tego stanowiska oscylują w granicach 3864-3834 BC.

${ }^{72}$ Winiger 1990, s. 297.

${ }^{73}$ Gross-Klee 1998, s. 249-256. Daty dla stanowiska obejmuja okres 3827-3804 BC. 
$\mathrm{KM}, \mathrm{KJ}$ i $\mathrm{KSch}^{74}$. W związku z tą grupa pozostają znaleziska talerzy z Bylan ${ }^{75}$ oraz Kučlina ${ }^{76}$. W cytowanych pracach znalazła się opinia M. Zapotockýego, iż GBN-V jest współczesna fazie I KM. Spotkało się to ze zdecydowaną krytyką ze strony J. Lüninga, który dowodzi, że zespół z Bylan należy datować, na podstawie obecności w nim pucharu tulipanowatego typu 6 i mis typu 1.2, na fazę III $\mathrm{KM}^{77}$. Dodatkowym argumentem za taką wersją datowania GBN-V jest obecność w jej zespołach elementów KSch. Tak więc pojawienie się talerzy na terenie Czech należałoby synchronizować z okresem 4000-3900 BC. Podkreślenia wymaga jednak fakt, że pojawienie się talerzy w GBN-V związane być mogło nie tyle z bezpośrednimi wpływami KM, ile z oddziaływaniami KSch, które były szczególnie wyraźne wśród grup $\mathrm{KJ}$ na terenie $\mathrm{Czech}^{78}$.

W tym czasie reminiscencje oddziaływań KM trafiają także do ugrupowań KMCM. Należy tu przytoczyć odkrycie na stanowisku Jezeřany-Maršovice. To południowomorawskie stanowisko KMCM datowane jest na fazy Ic oraz $\mathrm{Ib}^{79}$. Talerz jest najprawdopodobniej związany z młodszą fazą zasiedlenia stanowiska, którą można synchronizować z innymi jednostkami „niemalowanego lendzielu”, ${ }^{\text {"80 }}$. Odpowiadają temu uzyskane dla omawianego stanowiska daty radiowęglowe, które odnoszą się do okresu 3900-3800 BC ${ }^{81}$. Data radiowęglowa sugeruje, iż talerz pochodzi $\mathrm{z}$ najmłodszego (związanego $\mathrm{z}$ oddziaływaniami $\mathrm{KJ}$ ) odcinka istnienia KMCM.

Na północ od Czech talerze wystapiły w GB KPL. Stan badań nad GB KPL jest słaby. Do wyjątków należą rozpoznane choćby pobieżnie osady. Znane są jednak talerze z osad w Berlin-Britz, Döberitz, Burgdorf, Gatersleben, Schönermarkt i innych $^{82}$. Sporne pozostaje jednak datowanie najwcześniejszych zespołów GB KPL (Baalberg A). Według R. Gleslera i B. Höhn powstanie omawianej jednostki należy synchronizować z fazą II KM, wczesnej KSch i schyłku GG (około 4250-4000 $\mathrm{BC})^{83}$. E. Kirsch pojawienie się KPL w Brandenburgii i Meklemburgii datuje na około $4000 \mathrm{BC}^{84}$. J. Hoika przyjmuje natomiast, że powstanie GB KPL miało miejsce około $4350 \mathrm{BC}^{85}$. Jednak $\mathrm{z}$ uwagi na słaby stan badań trudno tu o jednoznaczne rozstrzygnięcia.

${ }^{74}$ Zapotocký 1991, s. 208; 1994, s. 258; 1998, s. 293.

${ }^{75}$ Zapotocký 1994, s. 258; 1998, s. 293.

${ }^{76}$ Petrlik, Zapotocký 1992; Zapotocký 1996.

${ }^{77}$ Lüning 1998, s. 280.

${ }^{78}$ Lüning 1976.

${ }^{79}$ Rakovský 1986, s. 243, 245; Kazdová, Koštuřik, Rakovský 1994, s. 139-147. Można mieć wątpliwości, czy w tym przypadku rzeczywiście jest to talerz.

${ }^{80}$ Np.: Lichardus, Vladar 1964; Podborský 1986; Vavra 1986; Pavelčik 1987; Kazdová, Koštuřik, Rakovský 1994.

${ }^{81}$ Košturik i inni 1984, s. 404.

${ }^{82}$ Preuss 1966, s. 26; Kirsch 1994, s. 52.

${ }^{83}$ Höhn 1998, s. 227; Gleser 1998, s. 239.

${ }^{84}$ Kirsch 1994, s. 149-154.

${ }^{85}$ Hoika 1990, s. 201. 
Północną granicę występowania talerzy tworzy kompleks grupy północnej KPL. Talerze pojawiają się w strefie Szlezwiku-Holsztynu w związku z GS (stanowisko w Siggeneben Süd $)^{86}$. Na podstawie dat radiowęglowych można sądzić, że grupa ta istniała $w$ okresie $4200-3700 \mathrm{BC}^{87}$. Talerze najprawdopodobniej występowaly również w - nieco późniejszej niż GS - GSa ${ }^{88}$. Jej rozwój należy zamknąć w okresie 3850-3500 BC $^{89}$. Najprawdopodobniej pośrednictwo GS lub/i GSa przyczyniło się do pojawienia się omawianej formy wśród inwentarzy jutlandzkiej GV (np. Stenga$\mathrm{de}^{90}$ ), której geneza przypada na około $4000 \mathrm{BC}^{91}$. Mniej więcej w tym samym czasie, tj. około $4000 \mathrm{BC}$, talerze pojawiają się wśród inwentarza ceramicznego GSva (np. Stengade, Havenlev ${ }^{92}$ ) na wyspach duńskich i jej odpowiednika w południowej Szwecji - GSve ${ }^{93}$. Nieco później, bo około 3850 , pojawiają się również w zelandzkiej GOx (np. Oxie, Sigersted) ${ }^{94}$.

Pozycja znalezisk z terenu Niżu Polski została już omówiona. Warto natomiast podkreślić ewentualną obecność talerzy - w omawianym horyzoncie chronologicznym - w małopolskich zespołach KPL (Karmanowice, stan. $35^{95}$; Gródek Nadbużny ${ }^{96}$ ). Tymczasem, $\mathrm{z}$ powodu moźliwości niehomogenności zespołów, pomijam talerze GO i GP-M (Racibórz-Ocice ${ }^{97}$ oraz Targowisko, stan. 1 i $2^{98}$ ).

W tak szerokim występowaniu talerzy największą rolę odegrały zapewne ugrupowania KM. Użyteczny będzie tu model wypracowany przez H. Schlichterle dla obszaru w rejonie Jeziora Bodeńskiego. Elementy KM występują tu w trzech strefach: Kernzone (strefa jądrowa), Randzone (strefa pograniczna) i Aussenzone (strefa zewnętrzna). Pierwsza związana jest ze zwartym osadnictwem ludności KM, druga jest strefą ekspansji i penetracji, trzecia zaś stanowi obszar „akulturacji michelsberskiej"99.

Wydaje się, że środkowoneolitycze znaleziska talerzy w „nie-michelsberskich” środowiskach kulturowych są związane z funkcjonowaniem owej strefy „,akulturacji michelsberskiej". Jej wewnętrzna struktura była zapewne niejednorodna. Na przykład, nad Renem ustanowiona zostaje ona ok. 4400/4300 BC (w związku z GE

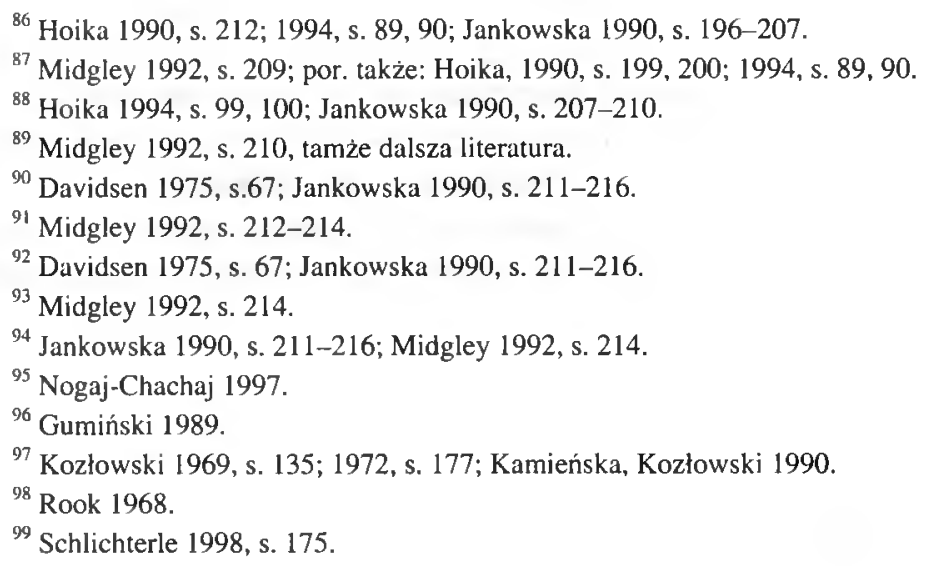


i GB-O, około $4100 \mathrm{BC}$ również $\mathrm{KSch}$ ) i trwa do końca interesującego nas okresu (KP, $\mathrm{KCa})$.

Prawdopodobne jest, że z ową nadreńską strefą cyrkulacji wzorców kulturowych związane są również znaleziska $\mathrm{z}$ terenu Czech (pośrednio Moraw?). Przy czym najprawdopodobniej napływ wzorców genetycznie michelsberskich dokonał się tu za pośrednictwem KSch. Nie da się jednak całkowicie wykluczyć - w świetle znalezisk z Mostu ${ }^{100}$ - możliwości bezpośrednich inspiracji ze strony KM.

W przypadku ugrupowań KPL podstawowa rola nadawcy impulsów kulturowych przeniesiona zostaje z południowych peryferii ugrupowań kultury Michelsberg na wschodnie. Wydaje się, że pouczająca może być sytuacja zaobserwowana na północnym skraju Harzu. W tym okresie na tym terenie funkcjonowało osadnictwo GG, GB KPL oraz wczesnej KM ${ }^{101}$. Pośrednictwo GB KPL lub bezpośrednie oddziaływania KM trafily wzdłuż Łaby na teren Szlezwiku-Holsztynu, do ugrupowań GS i GSa, skąd przekazane zostały dalej na północ - do GSv, GSve, GO i GV.

Obecność talerzy wśród kujawskich (szerzej - wschodniowielkodolinnych) ugrupowań KPL można potencjalnie łączyć z dwoma źródłami inspiracji: środowiskami GB KPL lub bezpośrednio KM z przedgórza Harzu. Do czasu pełniejszego poznania GB KPL jej pośrednictwo w przekazaniu talerzy na teren Kujaw już ok. 4400 BC musi budzić wątpliwości. Niezależnie jednak od tego, które z wymienionych ugrupowań było bezpośrednim „dawcą" talerzy, ich związek (pośredni lub bezpośredni) z KM jest bezsporny.

Powyższa teza uzyskuje dodatkowe potwierdzenie w analizie zdobnictwa występującego na talerzach. W kujawskich zespołach KPL zdobione talerze znane są ze stanowisk Sarnowo 1 (warstwa pod grobowcem 8) i 1A, Łącko 6 i 6A. Zdobnictwo talerzy można podzielić na dwie zasadnicze grupy. Pierwszą tworzą karbowania lub odciski zlokalizowane na krawędziach (np. Sarnowo 1A - ryc. 2: 6), drugą zaś zdobnictwo podkrawędne wewnętrzne w formie nakłuć/odcisków drobnych stempli (np. Sarnowo 1A, Łącko 6A - ryc. 2: 3, 7, 10). Oba typy zdobień talerzy bywają łączone $\mathrm{z}$ oddziaływaniami ,wstęgowymi" ${ }^{102}$. O wiele bardziej prawdopodobna jest jednak hipoteza zakładająca „michelsberskie” źródło owego zdobnictwa. Skłaniają do tego obserwacje talerzy KM. Zdobnictwo talerzy typu pierwszego jest powszechne na talerzach KM (np.: Miel, Mayen, Bad Neuheim ${ }^{103}$ ); można tam znaleźć również okazy zdobione identycznie (!) jak okazy z Sarnowa 1A i Łącka 6A (typ drugi zdobnictwa talerzy, np. Glaubergmuseum, Niedenstein, Altenbamberg ${ }^{104}$ ).

Być może obecność/nieobecność i zdobienie/brak zdobień talerzy są efektem zmian dynamiki kontaktów kujawskiej KPL z KM. W myśl tej interpretacji w fazie I

\footnotetext{
${ }^{100}$ Zapotocký, Cerna, Dobeš 1989.

${ }^{101}$ Gleser 1998, s. 242.

${ }^{102}$ Np. Wiklak 1983, s. 183.

${ }^{103}$ Lüning 1967, Tafeln 5, 6, 7, 11.

${ }^{104}$ Lüning 1967, Tafeln 14, 15, 23.
} 
KPL istniały względnie czytelne kontakty z KM (których identyfikatorem jest zarówno sama obecność omawianych form, jak i ich zdobnictwo). W fazie II zostają one jednak rozluźnione (mała ilość talerzy, brak zdobnictwa), by całkowicie (?) zniknąć w fazie IIIA. Co było przyczyną osłabienia kontaktów pomiędzy oboma wspomnianymi ugrupowaniami - trudno dociec. Być może ową narastającą w czasie „zaporę" stanowiła GB KPL. Obecność talerza w zespole z Krępcewa mogłaby więc świadczyć o trwaniu w rejonie Pyrzyc oddziaływań zachodnich po $3800 \mathrm{BC}$ (z powodu geograficznej bliskości GB KPL lub/i KM?).

Tak szybkiego napływu talerzy do jednostek sąsiadujących z KM nie da się zinterpretować poprawnie bez wiedzy o orientacji więzi kulturowych w okresie bezpośrednio poprzedzającym $4400 \mathrm{BC}$. Według R. Glesera około $4500 \mathrm{BC}$ na terenie Europy mamy do czynienia z rozległym systemem kulturowym - „fenomenem bischeimskim" ${ }^{105}$. W rozumieniu cytowanego autora był to równoleżnikowy system wymiany informacji, który objął GM, GB i KR (faza III), a więc obszary od Basenu Paryskiego na zachodzie - do górnej Łaby na wschodzie. Do owego systemu na zachodzie należy dołączyć KC (datowania radiowęglowe oraz obecność talerzy), natomiast na wschodzie ugrupowania KPCW I-IIa. Wśród ostatnich czytelne są bowiem oddziaływania ze strony $\mathrm{KR}^{106}$. W tym kontekście rozprzestrzenienie talerzy można odczytać jako efekt trwania wspomnianego równoleżnikowego systemu wymiany informacji.

Należy dodać, że koncepcja „fenomenu bischeimskiego" - w nieco rozszerzonej wersji - tworzy niezwykle ciekawą perspektywę. Otóż na zachodnim „biegunie” omawianego systemu wymiany informacji, już około 4500 BC znane są elementy, które na Kujawach (a więc we wschodniej ekspozyturze systemu) pojawią się w kontekście wczesnej KPL. Są to nie tylko interesujące nas talerze, lecz również grobowce bezkomorowe. Elementy te wystapiły na stanowiskach typu Passy KC ${ }^{107}$. Przedstawiona problematyka zostanie na nowo podjęta w powstającej pracy doktorskiej piszącego te słowa.

W niniejszym opracowaniu używa się terminu „talerz", mimo że sugeruje on stołową funkcję omawianej formy. O wiele słuszniej byłoby używać terminu „placek gliniany", lecz jest to niezgodne z tradycją polskiej nomenklatury.

Wśród funkcji dotychczas przypisywanych talerzom należy wymienić następujące: naczynia do jedzenia, do wypiekania chleba, do pieczenia, pokrywki i podstawki pod naczynia ${ }^{108}$. Najszerzej akceptowana jest hipoteza zakładająca, że talerze

\footnotetext{
${ }^{105}$ Gleser 1995, s. 312, 313.

${ }^{106}$ Czerniak 1979; 1980; 1994.

${ }^{107}$ Briard 1995, s. 8.

${ }^{108}$ Np. Lüning 1967, s. 61; Behrens 1963, s. 138.
} 
służyły pierwotnie jako naczynia do wypieku chłeba ${ }^{109}$. Według doświadczeń A. Wintera - talerze rozpalane na węglu drzewnym do temperatury $100-120^{\circ} \mathrm{C}$ na swej stronie zewnętrznej, pozwalały na wypiek podpłomyka w ciągu 10 minut i upieczenie mięsa w ciagu 13 minut ${ }^{110}$.

Używając określenia „chleb” nie należy oczywiście wyobrażać sobie współczesnego pieczywa. Z terenu ziem polskich brak znalezisk, które umożliwilyby choćby przybliżoną rekonstrukcję wyglądu i technologii wypieku neolitycznego pieczywa. Jedyne znane mi znalezisko całego „chleba” pochodzi z zachodnioszwajcarskiej osady KCa w Twann. Datowany jest on na okres 3560-3530 BC. Średnica podplomyka z Twann wynosi $65 \mathrm{~mm}$, przy wysokości $24 \mathrm{~mm}$ i wadze $25 \mathrm{~g}^{111}$.

Przyjmując, że udział przetworów ze zbóż był nieodmiennie wysoki, można twierdzić, że wytwory z mąki stanowiły stały składnik menu grup środkowoneolitycznych $^{112}$. Wytwarzanie chleba musiało być więc czynnością stosunkowo częstą.

Według XIX-wiecznych relacji z terenów obecnej Białorusi i Ukrainy najpowszechniejsze były dwa sposoby wypieku pieczywa. Pierwszy, najbardziej prymitywny, polegał na wypieku pieczywa z ciasta złożonego z mąki (czasem z dodatkiem kory lub kasztanów, suszonych jagód, miodu, soli) i wody. Uformowawszy niewielki podpłomyk kładziono go bezpośrednio na rozgrzanych węglach drzewnych. Drugi sposób był nieco bardziej skomplikowany. Przygotowanie ciasta było takie jak poprzednio, inna była natomiast technologia jego wypieku. Otóż przygotowywano duży płaski kamień (tzw. plita), rozgrzewano go na ognisku, smarowano jego powierzchnię kawałkiem słoniny nadzianej na patyk (w okresie postu mogło być to kilka kropel oleju), a następnie na tak przygotowaną powierzchnię kładziono uformowany, surowy podpłomyk (niekiedy wylewano na kamień ciasto). W efekcie wypieku powstawał niewielki „pampuch” lub „reczuch”, który dodatkowo mógł być smarowany słonina, cebula, czosnkiem lub miodem ${ }^{1: 3}$.

Najprawdopodobniej opisywane sposoby wypieku pieczywa nie różniły się zbytnio od metod stosowanych w neolicie. Dlaczego więc używano talerzy? Te wyjątkowo rzadkie formy nie mogły mieć podstawowego znaczenia w technologii wypieku pieczywa. Na przykład w chacie 3 w Przybranówku, na około 100-120 zniszczonych naczyń zaobserwowano jedynie dwa fragmenty talerza ${ }^{114}$. Na osadzie KSch w Ehrenstein, na 3081 naczyń zaobserwowano jedynie 32 fragmenty talerzy $^{115}$. Tak więc należy przypuszczać, że wypieku ciasta przy użyciu talerzy dokonywano sporadycznie. Nasuwa się zatem hipoteza o specjalnym statusie omawianej formy, związanym z symboliką chleba.

\footnotetext{
${ }^{1119}$ Co nie musi znaczyć, że wszystkie bez wyjątku talerze były naczyniami do wypiekania chleba.

${ }^{110}$ Lüning 1968.

${ }^{111}$ Wăhren 1990, s. 117.

${ }^{112}$ Gross, Jacomet, Schibler 1990, s. 112-114.

${ }^{113}$ Rokossowska 1899, s. 155; Gloger 1899, s. 341; Kubiak I., Kubiak K. 1981, s. 12.

114 Domańska, Rzepecki 2001.

${ }^{115}$ Lüning 1997, s. 57-66.
} 
Jeszcze sto lat temu na ziemiach polskich chleb był nie tylko potrawa, lecz także pewnym symbolem dostatku i pożywienia. Związany z ziarnem, wodą i ogniem, jako czynnikami generującymi jego powstanie, był nie tyle egzemplifikacją boskiej mocy kreacji, ile samym Bogiem. Przytoczyć tu można opinię I. i K. Kubiaków: „Spełniał [chleb - przyp. S.Rz.] swą kreacyjno-inicjalną rolę, gdyż traktowano go jako żywą boską istotę, posiadał więc właściwości antydiaboliczne"116. Nie tylko chleb, lecz wszystko, co związane było z jego powstaniem, miało znaczenie magiczne. „Proces przygotowania pieczywa był procesem niezwykłym, obwarowanym licznymi przepisami, co wolno, a czego nie, naszpikowanym licznymi zaklęcia-

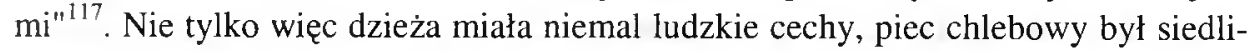
skiem diaboliczno-boskich sił, a łopata służąca do wkładania i wyjmowania chleba służyła wiedźmom do latania. Ta sama moc sprawiała, że stół, na którym spoczywał chleb, stawał się niemal ołtarzem, a akt krojenia chleba (pierwszego z wypieku) nożem zyskiwał wymiar zbrodni. Oczywiście sprawą najważniejszą był sam proces wypieku. Wznoszący się z pieca chlebowego dym, tworząc oś świata, łączył sferę życia ludzi z Bogiem, był droga, po której do Nieba uchodziły dusze zmarłych i zstępowały dusze nowo narodzonych (dlatego unikano wypieku chleba po śmierci bliskich, aby oszczędzić ich duszom cierpień, oraz zakopywano w pobliżu pieca łożysko). Akt wypieku był więc związany z przemianami, jakimi były śmierć czy narodziny. „Czynność ta [wypiek chleba - przyp. S.Rz.] podporządkowana jest opozycjom, jak surowe - pieczone, niejadalne - jadalne, niezdrowe - zdrowe, płynne stałe" ${ }^{118}$. Można powiedzieć więc, że chleb jako efekt stworzenia stanowił „wdarcie się sacrum w obręb świata" "119, był nieomal powtórzeniem aktu kosmogonii. Chleb miał nie tylko właściwości lecznicze, wróżebne, lecz również magiczne ${ }^{120}$. Symbolika chleba sprawiała również, że wiązany był on z kultami zboża i pomyślnych zbiorów. Epitet „Pani Chleba” był jednym z przydomków Izydy ${ }^{121}$.

Podsumowując niniejsze rozważania stwierdzimy, że talerze były naczyniami niezwykle rzadko występującymi, najczęściej w materiale z osad. Należy podkreślić ich związek z procesem wypieku chleba, przy czym z uwagi na częstotliwość ich występowania można przypuszczać, że był to wypiek o pozautylitarnym znaczeniu. Może więc talerze są wyrazem ,hierofanii chleba"122 , złożonego zespołu kultów związanych $z$ rytualnym wypiekiem i spożyciem chleba? Trudno na to pytanie jednoznacznie odpowiedzieć. Nasuwają się tu jednak skojarzenia z najstarszą wytwórczością miedzi, interpretowaną jako rytuał magiczny związany z pogłębianiem więzi

\footnotetext{
${ }^{116}$ Kubiak I., Kubiak K. 1981, s. 142.

${ }^{117}$ Kubiak I., Kubiak K. 1981, s. 10.

${ }^{118}$ Kubiak 1., Kubiak K. 1981, s. 126.

${ }^{119}$ Eliade 1993, s. 72.

${ }^{120}$ Kubiak I., Kubiak K. 1981.

${ }^{121}$ Frazer 1996, s. 320.

${ }^{122}$ Eliade 1993, s. 161, 162.
} 
między członkami jednej grupy społecznej ${ }^{123}$. Oczywiście nie chodzi tu o treść rytuału, lecz jego strukturę: przemianę w ogniu, której świadkami i konsumentami byli uczestnicy rytuału.

Niezależnie od akceptacji czy negacji powyższej interpretacji, wiązanie pojawienia się talerzy nie tylko w późnym ${ }^{124}$, ale i środkowym neolicie, $z$ oddziaływaniami zachodnioeuropejskimi pozwala na nowe spojrzenie na zagadnienie genezy kujawskiej KPL. W ciągu ostatnich dziesięciu lat w żywo prowadzonych dyskusjach na plan pierwszy zdecydowanie wysunął się południowo-wschodni kierunek poszukiwañ $^{125}$. Mam nadzieję, że prezentowana praca zarysuje pewną równowagę. Na przykładzie talerzy daje się bowiem zauważyć, że udział pierwiastka „zachodniego" był niezwykle ważny od samego początku istnienia KPL na terenie obecnej Polski. Bardziej szczegółowe i ograniczone przestrzennie tylko do Kujaw rozważania na ten temat zostaną podjęte przez autora w niedalekiej przyszłości.

\section{BIBLIOGRAFIA}

\section{A. Wy kaz skrótów}

Die ersten Bauern - Die ersten Bauern. Pfalbaufunde Europas, Bd. 1 und 2, Zürich 1990 Internationales Symposium - Internationales Symposium über die Lengyel-Kultur 1888-1988. ZnojmoKravsko-Tesetice 3.-7.10.1988, Brno - Łódź 1994

MK - Die Michelsberger Kultur und ihre Randgebiete - Probleme der Entstehung, Chronologie und des Siedlungswesens. Kolloquium Hemmenhofen, 2123.2.1997 (Hrsg. J. Biel, H. Schlichterle, M. Strobel, A. Zeeb), Stuttgart 1998

PMMAE - Prace i Materialy Muzeum Archeologicznego i Etnograficznego w Lodzi. Seria Archeologiczna, Łódź

\section{B. Literatura}

Arnal J., Burenez C.

1958 Die Struktur des französischen Neolithikums auf Grund neuester stratigraphischer Beobachtungen, Bericht der Römisch-Germanischen Kommission, Bd. 37-38, s. 1-90.

B a illoud G.

1961 Les disques en terre cuite (,.plats-à-pain”) dans le Néolithique français, (w:) L'Europe à la fin de l'âge de la pierre, Praha, s. 509-514.

1971 Le Néolithique danubien et le Chasseen dans le Nord et le centre de la France, (w:) Fundamenta, Reihe A, Bd.. 3, s. 201-245.

\footnotetext{
${ }^{123}$ Kuna 1989, s. 34-36.

${ }^{124}$ Kośko 1982

${ }^{125}$ Np. Czerniak 1994; Kukawka 1997.
} 
Behrens H.

1963 Tonscheiben (,Backteller”) aus dem mitteldeutschen Neolithikum, Jahresschrift für mitteldeutsche Vorgeschichte, Bd. 47, s. 127-144.

B i 11 a mboz A.

1998 Die jungneolithischen Dendrodaten der Pfalbausiedlungen Südwestdeutschland als Zeitrahmen für die Einflüsse der Michelsberger Kultur in ihren südwestlichen Randgebiet, (w:) MK, s. 159-168.

B riard J.

1995 Les mégalithes de L'Europe atlantique. Architecture et art. Funéraire (5000-2000 avant J.-C.), Paris.

Chmielewski W.

1952 Zagadnienie grobowców kujawskich w świetle ostatnich badań [Rés. Le problème des sèpultures de Cuyaviae dans la lumière de recentes études], Lódź.

Czebreszuk J., Szm y t M.

1992 Osadnictwo neolityczne $i$ wczesnobrąowe w Dębach woj. wtoctawskie, stanowisko 29 [Sum. The Neolithic and Early Bronze Settlement at Dęby, Włocławek Voivodeship, Site 29], Poznań - Inowrocław.

Czerniak L.

1979 Z badań nad problematykq równoleżnikowych kontaktów kulturowych spoleczeństw dorzeczy Odry $i$ Wisly w mlodszej epoce kamienia (Zagadnienie tzw. wplywów kultury rösseńskiej) [Sum. Cultural Contacts of the Younger Stone Age Communites in the Odra and Vistula Basins (The Problem of the so-called Influences of the Rössen Culture)], „Wiadomości Archeologiczne", t. XLIV, s. 123-131.

1980 Rozwój spoleczeństw kultury póżnej ceramiki wstęgowej na Kujawach [Sum. The Development of the Late Band Pottery Culture in Kujawy], Poznan.

1994 Wczesny i środkowy okres neolitu na Kujawach. 5400-3650 p.n.e. [Sum. Early and Middle Period of the Neolithic in Kuiavia], Poznan.

Czerniak L., Kośk o A.

$1993 Z$ Z badań nad genezq i rozwojem kultury pucharów lejkowatych na Kujawach [Sum. Studies on the Origin of the Development and Systematics of Funnel Beaker Culture in Kujawy], Poznań.

Davidsen K.

1973 Neolitiske lerskiver belyst af danske fund. Neolithische Tonschieben aus der Perspektive dänischer Funde, „Aarbøger”, s. 5-72.

Dieckmann B.

1991 Die Kulturgruppen Wauwil und Straßburg im Kaiserstuhlgebiet, (w:) Die Kugelbechergruppen in der sïdliche Oberrheinebene, Ridisheim, s. 7-60.

Domańska L.

1995 Geneza krzemieniarstwa kultury pucharów lejkowatych na Kujawach [Sum. The Origin of the Flint Industry of the TRB in Kuyavia], Łódź.

Domańska L., Kośko A.

1983 Łącko, woj. Bydgoszcz, stanowisko 6 - obozowisko z fazy I („AB") kultury pucharów lejkowatych. $Z$ badań nad geneza rozwoju i systematyka chronologiczna kultury pucharów lejkowatych na Kujawach [Sum. Łącko, district Bydgoszcz, site no. 6. The Camp From Stage "AB" KPL], „Acta Universitatis Lodziensis. Folia Archaeologica", t. 4, s. 3-48.

Domańs ka L., Rze pecki S.

2001 Osiedla kultury pucharów lejkowatych ze stanowiska Przybranówek 43, gm. Aleksandrów Kujawski, w świetle badań przeprowadzonych w latach 1994-1997 [Sum. Funnel Beaker 
Culture settlements on site Przybranówek 43. Aleksandrów Kujawski commune. in the light of research in the years 1994-1997], „Eódzkie Sprawozdania Archeologiczne”, t. VII. s. $13-62$.

Dubouloz J.

1998 Réflexions sur le Michelsberg ancien en Bassin parisien, (w:) MK, s. 9-20. Eli a d e M.

1993 Sacrum. Mit. Historia, Warszawa.

Frazer G.J.

1996 Zlota gataź, Warszawa.

Gabałówna L.

1970 Wyniki analizy C-14 węgli drzewnych z cmentarzyska kultury pucharów lejkowatych na stanowisku 1 w Sarnowie - z grobowca 8 i niektóre problemy z nimi zwiqzane. Informacja wstepna [Sum. A Note on the Radiocarbon Dating of Charcoal from the TRB Cemetery on Site 1 at Sarnowo (barrow 8) and Certain Related Problems], PMMAE, nr 17, s. 77-91.

Gleser R.

1995 Die Epi-Rössener Gruppen in Südwestdeutschland. Untersuchungen zur Chronologie, stilistischen Entwicklung und kulturellen Einordnung, Bonn.

1998 Periodiesierung, Verbreitung und Entstehung der älteren Michelsberger Kultur, (w:) MK, s. 237-247.

G loger $Z$.

1899 O chlebie $i$ zwyczajach u ludu w Tykocinskim, „Wisła”, t. XII, s. 336-343.

Gross E., Jacomet S., Schibler J.

1990 Selbstversorgung in neolithischen Dörfern am Zürichsee, (w:) Die ersten Bauern, Bd. 1, s. $105-116$.

Gross E., Ritz m a n $\mathrm{Ch}$.

1990 Die neolithischen und bronzezeitlichen Siedlungen im Zürcher Seefeld, (w:) Die ersten Bauern, Bd. 1, s. 161-176.

Gross-Kle e E.

1998 Michelsberg: Heteregonität und kulturell Einbindung in Raun und Zeit, (w:) MK, s. 249259.

Gumiński W.

1989 Gródek Nadbużny. Osada kultury pucharów lejkowatych [Sum. Gródek Nadbużny. A Settlement of the Funnel Beaker Culture], Wrocław - Warszawa - Kraków - Gdańsk - Łódź.

$\mathrm{HöhnB.}$

1998 Korrespondenzenanalyse und chronologische Gliederung Michelsberger Gefässformen, (w:) MK, s. 121-126.

$\mathrm{Hoik} \mathrm{a} \mathrm{J}$.

1990 Zum Übergang vom Früh- zum Mittelneolithikum in der Trichterbecherkultur, (w:) Die Trichterbecherkultur. Neue Forschungen und Hypothesen. Material des Internationalen Symposiums Dymaczewo, 20-24 1988, Teil I (red. D. Jankowska). Poznań, s. 197-217.

1994 Zur Gliederung der frühneolithischen Trichterbecherkultur in Holstein, (w:) Beiträge zur frühneolithischen Trichterbecherkultur im westlichen Ostseegebiet, Neumünster, s. 85-130.

J a n k ow ska D.

1990 Spoteczności strefy potudniowo-zachodniobaltyckiej $w$ dobie neolityzacji [Zus. Gemeinschaften des südwestlichen Ostseeraums in der Neolithisierungszeit], Poznań.

J a żdżewski K.

1970 Wzajemny stosunek do siebie elementów pólnocnych, poludniowych i zachodnich w obrębie kultury pucharów lejkowatych [Zus. Das Verhältnis des nördlichen, südlichen und westlichen Einschlages zueinander innerhalb der Trichterbecherkultur], PMMAE, nr 17, s. 49-76. 
Jeunesse Ch.

1990 Le néolithique alsacien et ses relations avec les régions voisines, Die ersten Bauern, Bd. 2, s. $177-194$.

1998 Pour une orgine occidentale de la culture de Michelsberg? (w:) MK, s. 29-45.

Kamieńska J., Kozłowski J.K.

1990 Entwicklung und Gliederung der Lengyel-und Polgar-Kulturgruppen in Polen, Kraków.

Kaz dová E., Koštuřik P., R a kovský I.

1994 Der gegenwärtige Forschungsstand der Kultur mit mährischen bemalter Keramik, (w:) Internationales Symposium, s. 131-155.

Ke efer E.

1988 Hochdorf II. Eine jungsteinzeitliche Siedlung der Schussenrieder Kultur, Stuttgart.

Kirsch E.

1994 Beiträge zur älteren Trichterbecherkultur in Brandenburg, Potsdam.

Kośko A.

1981 Udzial potudniowo-wschodnioeuropejskich wzorców kulturowych $w$ rozwoju niżowych spoleczeństw kultury pucharów lejkowatych. Grupa matewska [Sum. The Share of the South-East European Cultural Models in the Development of Lowland Communites of Funnel Beaker Culture. The Mątwy Group], Poznań.

$1982 Z$ Z badań nad problematykq równoleżnikowych kontaktów kulturowych spoteczenistw dorzeczy Odry $i$ Wisty w mtodszej epoce kamienia (Zagadnienie tzw. wptywów kultury michelsberskiej) [Sum. Research on the Latitundinal Cultural Contacts Between Societes in the River Basins of the Oder and Vistula in the Neolithic (The Question of the so-called "Influence of the Michelsberg Culture")], „Wiadomości Archeologiczne”, t. XLVII, s. $161-167$.

Kośko A., Prinke A.

1975 Sierakowo, woj. Bydgoszcz, stan. 8 - osada z fazy II (wczesnowióreckiej) kultury pucharów lejkowatych [Sum. Sierakowo, Voivodeship of Bydgoszcz, Site 8 - Settlement From the IInd (Early Wiórek) Stage of the Funnel Beaker Culture], „Fontes Archaeologici Posnanienses", vol. XXVI, s. 1-42.

Koštur̆ik P.. Rakovský I., Peške L., Pŕichysta A., S a laš M., S voboda J.

1991 Sidlište mladšiho stupně kultury s moravskou malovanou keramikou v JezeranechMaršovicich, „Archeologicke Rozhledy”, t. XXXVI, s. 378-410.

Koz lowski J.K.

1969 Grupa ocicka kultury niemalowanej ceramiki typu morawskiego, Badania Archeologiczne na Górnym Śląsku w roku 1966, Śląski Instytut Naukowy, „Zeszyty Naukowe”, nr 13, s. $128-143$.

1972 Wielkokulturowe stanowisko eneolityczne w Raciborzu-Ocicach w świetle badań z lat 1960 1962, „Rocznik Muzeum Górnośląskiego w Bytomiu”, nr 10, s. 65-98.

Kubiak I., Kubiak K.

1981 Chleb w tradycji ludowej, Warszawa.

Kukawka S.

1997 Na rubieży środkowoeuropejskiego świata wczesnorolniczego. Społeczności Ziemi Chetminskiej w IV tysiqcleciu p.n.e. [Sum. On the Boundary of the Early Agrarian World. The Communites of Chełmno Land From IV Thousand Years BC], Toruń.

Kun a $\mathrm{M}$.

1989 Soziale und ökonomische Faktoren der Entwicklung der frühen Kupfermetallurgie in Südost- und Mitteleuropa, „Praehistorica”, Bd. XV, s. 33-38.

Lichardus J.

1998 Die Michelsberger Kultur strukturell gesehen, (w:) MK, s. 261-275. 
Lichardus J., Vladar J.

1964 Zu Problemen der Ludanice Gruppe in der Slowakei, "Slovenska Archeologia", t. 12, s. $69-162$.

Li pińska A.

1962 Slady osadnictwa kultury pucharów lejkowatych w Kotowie, pow. Nowy Tomyśl [Rés. Traces de la colonisation de la civilisation des coupes à col en forme d'entonnoir à Kotowo, dist. de Nowy Tomyśl], „Fontes Archaeologici Posnanienses”, t. 13, s. 303-310.

Lü n ing J.

1968 Die Michelsberger Kultur. Ihre Funde in zeitlicher und räumlicher Gliederung, „Bericht der Römisch-Germanischen Kommission", Bd. 48, s. 1-350.

1969 Die Entwicklung der Keramik beim Übergang vom Mittel-zum Jungneolithikum in süddeutschen Raum, „Bericht der Römisch-Germanischen Kommission”, Bd. 50, s. 1-96.

1976 Schussenried und Jordansmühl, Fundamenta, Reihe A, Bd. 3, s. 122-187.

1996 Erneute Gedanken zur Benennung neolithischen Perioden, „Germania”, Bd. 74, s. 233-237.

1997 Die Keramik von Ehrenstein, (w:) Das jungsteinzeitliche Dorf Ehrenstein, Stuttgart, s. 9-93.

1998 Betrachtungen ïber die Michelsberger Kultur, (w:) MK, s. 277-289.

Lün ing J., Z ürn H.

1977 Die Schussenrieder Siedlung im „Schlösslesfeld”, Markung Ludwigsburg, Stuttgart. Midgle y $\mathrm{M}$.

1992 TRB Culture. The First Farmers of the North European Plain, Edinburgh.

$\mathrm{N}$ i es i ołowska E.

1994 Einige Probleme der frühen Trichterbecherkultur in Polen, (w:) Beiträge zur frïhneolithischen Trichterbecherkultur im westlichen Ostseegebiet, Neumünster, s. 325-346.

Nog a j-Chachaj J.

1997 Dziewiaty sezon badań na sianowisku 35 w Kannanowicach, woj. lubelskie [Sum. The Ninth Field Season at Karmanowice, Site 35, Lublin Voivodeship], „Archeologia Polski Środkowowschodniej", t. II, s. 16-23.

Pavel č ik J.

1987 Moravia at the Decline of the Older Neolithic [Sum. Late Lengyel Groups and the Funnel Beaker Culture], (w:) Neolit i wczesna epoka brqzu na Ziemi Chełmińskiej (red. T. Wiślański), Toruń, s. 371-396.

Petrlik J.,Zapotocký M.

1992 Horka u Kučlina, okr. Tepelice - nové pravéké výšinné sídliště v Pokuñohoři, „Archeologicke Rozhledy", t. XLIV, s. 10-28.

Podborský V.

1986 Die Chronologie und kulturelle Verbindungen zur Zeit der Kulturen Spätlengyel-Bajč-RetzKr̈epice in Mitteldonaugebiet, „Praehistorica”, Bd. XV, s. 55-60.

Preuss J.

1966 Die Baalberger Gruppe in Mitteldeutschland, Berlin.

Rakovský I.

1986 Die neuesten Ergebnisse der Erforschung des Äneolithikums in Nordmähren, „Praehistorica", Bd. XV, s. 61-66.

Rokos sowska Z.

1899 Chleb. Przyczynki, „Wisła”, t. XIII, s. 153-158.

R ook E.

1968 Osady cyklu wstęgowego w Targowisku, pow. Bochnia [Rés. Les colonies de civilisation du cycle de la ceramique rubanee à Targowisko, district de Bochnia], „Materiały Archeologiczne" t. 9, s. 91-135. 
Rzepecki S.

2001 Czynniki wewnętrzne i zewnętrzne w rozwoju środkowoneolitycznych spoleczeństw kultury pucharów lejkowatych na Kujawach, Łódź (maszynopis pracy doktorskiej w bibliotece Instytutu Archeologii Uniwersytetu Łódzkiego).

$\mathrm{Schlenker} B$.

1998 Michelsberger Keramik aus Kulturschichten der Pfyner Kultur des Bodenseegebietes, (w:) MK, s. 177-184.

Schlichterle H.

1990 Siedlungen und Funde jungsteinzeitlicher Kulturgruppen zwischen Bodensee und Federsee, (w:) Die ersten Bauem, Bd. 2, s. 135-156.

1998 Was sucht Michelsberg in den Ufersiedlungen des Bodensees, (w:) MK, s. 169-175.

$\mathrm{Sch}$ wabedisen $\mathrm{H}$.

1967 Ein horizontierter „Breikeil” aus Satrup und die manigfachen Kulturverbindungen des beginnenden Neolithikums im Norden und Westen, „Paleohistoria”, t. XII, s. 409-468.

Stempin A.

1995 Osada ludności kultury pucharów lejkowatych na stanowisku Kietczewo 45, gm. Kościan, woj. leszczyńskie - analiza źródel nieruchomych i materialu ceramicznego [Zus. Siedlung der Bevölkerung der Trichterbecherkultur in Kiełczewo, Gem. Kościan, Woi. Leszno, Fundstelle 45 - Analyse der Inmobilen und keramischen Befunde], „Wielkopolskie Sprawozdania Archeologiczne", t. III, s. 13-29.

Vavra $\mathrm{M}$.

1986 Die Jordanów-Gruppe Böhmens, „Praehistorica”, Bd. XV, s. 67-70.

Wăhen M.

1990 Brot und Getreide in der Urgeschichte, (w:) Die ersten Bauern, Bd. I, s. 117-118.

Wessel I.

1996 Die mittelneolithische Keramik des Hopfenberges, Berghausen, Ldkr. Karlsruhe, „Fundberichte aus Baden-Würtemberg", Bd. 21, s. 107-178.

Wiklak H.

1980 Wyniki badań wykopaliskowych w obrębie grobowca $8 w$ Samowie $w$ woj. włocławskim [Sum. Results of Excavations of Barrow 8 at Sarnowo, Province of Włocławek], PMMAE, nr 27, s. 33-83.

1983 Wyniki badań wykopaliskowych w osadzie i na cmentarzysku kultury pucharów lejkowatych na stanowisku IA w Sarnowie, woj. wloclawskie [Sum. Results of the Excavations of a Settlement and Cemetery of the Sarnowo Phase of the Funnel Beaker Culture on Site 1A at Sarnowo, Włocławek Province], PMMAE, nr 30, s. 167-200.

1990 Z badań nad osadnictwem fazy sarnowskiej kultury pucharów lejkowatych $w$ Sarnowie na Kujawach [Sum. Note on the Studies of the Funnel Beaker Culture Settlement, the Sarnowo Phase, at Sarnowo, Kuyavia], „Sprawozdania Archeologiczne”, t. XLIl, s. 109-127.

W ill m s Ch.

1998 Dendrochronologie und Gliederung der Michelsberger Kultur - Rückblick und Ausblick, (w:) MK, s. 231-235.

W in iger $\mathrm{J}$.

1990 Die prähistorische Besiedlungsstruktur der Bielersslandschaft, (w:) Die ersten Bauern, Bd. I, s. 297-306.

Wiślański T.

1970 Uwagi o grupie górowskiej kultury lendzielskiej w Polsce zachodniej [Sum. Remarks concerning the Góra Group of the Lengyel Culture in West Poland], „Archeologia Polski”, t. XVI, s. 39-105. 
1977 Bezkomorowy grobowiec megalityczny (tzw. kujawski) w Krępcewie nad Ina, stan. 4, gm. Kolin, woj. Szczecin [Sum. A Megalithic Unchambered Long Barrows (so-called Kuyavian Grave) at Krępcewo on the River Ina, Site 4, Commune of Kolin, Province of Szczecin], „Sprawozdania Archeologiczne”, t. XXIX. s. 83-100.

1979 Ksztattowanie się miejscowych kultur rolniczo-hodowlanych. Plemiona kultury pucharów lejkowatych, (w:) Prahistoria ziem polskich, t. II. Neolit (red. W. Hensel, T. Wiślański), Wrocław - Warszawa - Kraków - Gdańsk.

1983 Rola Pomorza w mtodszej epoce kamienia, (w:) Problemy epoki kamienia, Słupsk, s. 41-59. Wiślański T., Czarnecki M.

1970 Osada kultury pucharów lejkowatych w Kosinie, pow. Pyrzyce (stanowisko 6) [Zus. Eine Siedlung der Trichterbecherkultur in Kosin, Kreis Pyrzyce (Fundstelle 6)] „Materiały Zachodniopomorskie", t. XVI, s. 73-105.

Wojciechowski W.

1972 Osada ludności grupy brzesko-kujawskiej kultury lendzielskiej w Sicinach, pow. Góra [Sum. A settlement of the Brześć-Kujawy Group of the Lengyel Culture at Siciny, Góra District], „Wiadomości Archeologiczne”, t. XXXVII, s. 256-276.

Zapotocký M.

1991 Michelsberg und die relative Chronologie des frühen und älteren Äneolithikums in Böhmen, (w:) Die Trichterbecherkultur. Neue Forschungen und Hypothesen. Material des Internationalen Symposiums Dymaczewo, 20-24 1988, Teil I (red. D. Jankowska), Poznań, s. 201211.

1994 Beziehungen der Lengyel-Kultur und der Trichterbecherkultur im Lichte der neueren Funde aus Böhmen, (w:) Internationales Symposium, s. 256-262.

1996 Rany Eneolit v severočeském Polabi, ,Archeologické Rozhledy”, t. XLVIII, s. 404-459.

1998 Zum Stand der Forschung über die relative Chronologie des frühen Äneolithikums in Böhmen, (w:) MK, s. 291-302.

Z a potocký M., Č er na E., Době̌ M.

1989 Michelsberské nálezy ze severozápadnich Cech. „Pámatky Archeologické”, LXXX, s. 30-58.

\title{
THE MIDDLE NEOLITHIC PLATES FINDINGS FROM THE POLISH LOWLAND
}

\author{
Su m m a ry
}

Plates known as Essterllen. Tellern, Backtellern, Tonscheiben, and plat-á-plain were part of the Funnel Beaker Culture (FBC) material culture in the years $4400-3800 \mathrm{BC}$. In the first phase of FBC (4400-4000 BC) the plates were only registered in the Kujavia region. They are known from four sites: Łącko, site 6; Łącko, site 6A; Sarnowo, site 1A; Sarnowo, site 1 (graves 4 and 8). Both ornamented (with impressed decoration near the rim) and non-ornamented plates are known from this phase. Plates from the second phase of FBC are also registered in Kujavia (Inowrocław, site 95; Przybranówek, site 43) as well as in Wielkopolska (Kiełczewo, site 45) and in Pyrzyce region (Kosin, site 6). Plates from this phase lack any decoration. The only exception is the settlement at Krępcewo 6, dated to the period ca. 4000-3650 BC. Only one plate fragment was found there within an embankment of the grave. The plates disappear from Kujavia as early as about 3800 BC. The process of their disappearance among Kujavian FBC communities can be observed in the settlement at Przybranówek, site 43. Houses 1, 2, and 3 from phase II of this culture as well as house 4 from phase II/IIA contained fragments of plates. 
They were absent, however, in house 5 from phase IIIA. Altogether, 75 fragments of plates were analyzed from sites mentioned above.

An interregional analysis makes it possible to put forward a hypothesis that the first plates appeared about $4500 \mathrm{BC}$ in the Paris Basin and should be linked with materials of the Cerny culture and Menneville group. They were later adopted by the Michelsberg culture becoming one of its leading objects. Its further transmission into the cultural units bordering with the Michelsberg culture should be most probably linked with the 'Michelsberg acculturation' zone. Western part of this zone was formed about $4400 / 4300 \mathrm{BC}$ in the Rhine Basin. It is when the plates became part of assemblages of the Entzheim and Breubach-Obergarben groups and later also of the Schussenried culture (about $4100 \mathrm{BC}$ ). The Rhine route of plates dispersal into the south was continued in the following centuries. This is proven by the presence of plates in the territories of Pfyn and Cortaillod cultures. It was probably the Schussenried culture from where the plates were moved into the Czech groups: Bylany and Nadevsi and further to the east to Moravia, especially to the Moravian Painted Pottery culture.

The lowlands, dispersal of plates should most probably be linked with groups of the Michelsberg culture, which occupied north edge of the Harz mountains. It was undoubtedly the area from which the plates came to Kujavia (around $4400 \mathrm{BC}$ ), the Baalberg group of $\mathrm{FBC}$, and later to the Siggeneben and Satrup groups of FBC from Schlezwig-Holstein (about 4200 BC). From the later location they were further distributed into Scandinavian FBC groups such as Volling, Svalekllint and Svenstrop (about $4000 \mathrm{BC}$ ) and later the Oxie group (3850 BC).

The decoration of Kujavian plates is another proof of contacts with the Michelsberg culture. The plates themselves might indicate dynamic changes in contacts between FBC from Kujavia and the Michelsberg culture from the Harz mountains. These contacts are visible both in ornamentation and morphology in phase I, and only in morphology in phase II. No traces of contacts with the Michelsberg culture are detectable in phase IIIA in Kujavia.

The author links a very dynamic distribution of plates with the horizon proceeding $4400 \mathrm{BC}$. This proposal is a modification of "the Bischem phenomenon" put forward by Ralf Gleser. Numerous communities from cultures such as Cerny and Rössen and groups such as Menneville, Bischem as well as the Late Band Pottery Culture communities from Kujavia are part of a large latitudinal system of information exchange. According to the proposed hypothesis, presence of plates is a proof of existence of this system of information exchange in different cultural milieus.

Interpretation of FBC plates is proposed in the third part of the paper. The author argues that they served for bread baking. However, considering their very small number (e.g. at Przybranówek 3 only one fragment of plate out of one hundred vessels was noticed) they must have been of special significance. The Neolithic people have probably baked most of their bread directly on the fire or the heated stone slabs. Consequently, the plates might be materials remains of "bread hierophany" - a complex belief connected with ritual bread baking and consumption. 